\title{
QUESTÕES ÉTICAS PARA BIBLIOTECÁRIOS ${ }^{1}$ ETHICAL ISSUE FOR LIBRARIANS
}

\author{
Francisca Rasche \\ Mestranda em Ciência da Informação, \\ Universidade Federal de Santa Ctarina \\ franrasche@ced.ufsc.br
}

\begin{abstract}
RESUMO
Aborda a ética bibliotecária compreendendo a constituição da biblioteconomia a partir de uma visão sistêmica. Dessa forma, com o objetivo de levantar questões para discutir ética profissional, situa os bibliotecários no mundo do trabalho e pontua aproximações, entre o contexto de atuação e de relação dos profissionais em questão, com a ética dos direitos humanos e da alteridade.
\end{abstract}

PALAVRAS-CHAVE: Ética Bibliotecária. Ética e Informação. Ética em Bibliotecas.

\section{INTRODUÇÃO}

A ética, como um campo de estudo e reflexão em torno da conduta humana, é objeto da Filosofia. Porém, refletir sobre a ética não se restringe apenas ao campo da Filosofia. Em diferentes áreas do saber a ética vem ganhando espaço, servem como exemplo trabalhos como, "a sociedade em busca de valores" (MORIN, 1996) que reúne ensaios de autores diversos. No que diz respeito à ética profissional, tal emergência da temática ganha amplitude, quando o agir de membros de um determinado grupo tende a interferir, de modo decisivo, sobre si mesmo, sobre seus colegas ou sobre a sociedade como um todo. Embora sem fazer uso de uma linguagem filosófica e sem pretender aprofundar o tema, contribuindo teórica e filosoficamente com tal discussão, neste artigo abordar-se-á a ética como forma de refletir sobre o contexto de atuação e de relações dos profissionais bibliotecários.

Dentre algumas das questões voltadas à discussão sobre ética profissional, estão o modo como as profissões se constituem e como elas vêm assumindo seu papel na sociedade contemporânea?

No que diz respeito à sua constituição, toma-se como parâmetro à visão sistêmica de Freidson (1998) pois considera que uma profissão se compõe a partir de elementos como $a$ expertise, credencialismo e autonomia. Em outras palavras, em uma atividade humana,

\footnotetext{
${ }^{1}$ Artigo elaborado com base em texto inicialmente preparado para palestra proferida no $1^{\circ}$ Encontro de Ética para Bibliotecários do Estado de São Paulo promovido pelo Conselho Regional de Biblioteconomia $8^{\mathrm{a}}$ Região, realizado em 4 de setembro de 2004, na Biblioteca Mário de Andrade, São Paulo (SP).
} 
conhecimentos, técnicas e competências são produzidos, comunicados ou praticados por mais de um membro da sociedade, constituindo um grupo e, assim, integrando um empreendimento de ordem econômica, política e social. Desse modo, observam-se fenômenos como a profissionalização, em que uma ocupação organizada cuida da qualidade de suas tarefas e de seus benefícios para a sociedade, obtendo, dessa maneira, o direito de realizar um determinado tipo de trabalho, controlar o treinamento e o acesso a ele e, além disso, determinar a maneira de executá-lo (FREIDSON, 1998).

Em relação à importância que as profissões assumem na sociedade Giddens (1991) mostra que, embora a maioria das pessoas não consulte, periodicamente, profissionais especializados, o conhecimento de tais profissionais está integrado nos sistemas sociais. Isso porque, conforme o autor, a natureza das instituições modernas está profundamente ligada a mecanismos de confiança em sistemas abstratos e, tais sistemas, estão representados pelo que se chama de fichas simbólicas (dinheiro) e sistemas peritos (excelência técnica, competência profissional e o conhecimento perito). Exemplificando, um médico consultado ocasionalmente é um estranho, no qual confia-se por ser um profissional "médico", não porque há um conhecimento ou manutenção de algum tipo de relação pessoal com o mesmo. A confiança se estabelece pelo domínio de um conjunto de técnicas, de competências que o faz reconhecido como um perito em saúde.

O bibliotecário é um perito em armazenar, organizar e viabilizar o acesso à informação registrada, respondendo geralmente a problemas relacionados com a informação e as instituições como bibliotecas, centros de documentação e centros de informação. Em atividades que congregam diferentes técnicas e conhecimentos, exigindo determinadas competências, o bibliotecário participa de processos que tornam a informação utilizável para diferentes membros da sociedade, seja com fins acadêmicos, de estudo, de pesquisa, de autoformação, de cidadania ou de trabalho, permitindo seu uso por instituições, organizações, nações e, dessa forma, pela sociedade como um todo.

É por esses elementos, relativos ao fazer desse profissional — aos conhecimentos necessários para sua atuação, bem como, para a construção de argumentos que creditam sua prática, o modo como os membros da ocupação se organizam e, especialmente, a importância que a informação adquire frente aos modos de produção de existência humana na sociedade - que a biblioteconomia se constitui como uma profissão. Dessa forma, este artigo propõe uma reflexão sobre uma ética bibliotecária, preocupando-se com a conduta de tais profissionais e o estudo em torno de conduta dos membros da profissão. Essa proposta se dá a partir de uma abordagem que pensa a biblioteca como um ambiente de relações, a informação 
como um bem social e o bibliotecário como um ator social imerso num sistema ocupacional e num mundo do trabalho em processo de mudanças constantes.

\section{2 ÉTICA VERSUS ÉTICA PROFISSIONAL (OU DEONTOLOGIA?)}

A ética diz respeito ao ser humano e à sua dimensão de ser social. Tomando-se como base às proposições da sociologia do conhecimento desenvolvidas por Berger e Luckmann (1995), pode-se considerar a ética como uma construção social. Assim, a ética pode ser compreendida como algo vivo. Vivo para expressar que, de um lado, ao longo do processo civilizatório humano a ética recebe diferentes abordagens, conforme se modificam as condições materiais, tecnológicas, estéticas, intelectuais e culturais humanas. De outro lado, pode ser compreendida como dotada de vida, porque não é qualquer coisa exterior aos homens, não deve ser vista como um cânone sagrado, mas sim, como resultado da própria ação dos homens da qual todos são partícipes, participamos de sua construção.

A busca do bem como finalidade da ética, como propunha Aristóteles (1985) traz presente o desafio de uma conduta diária baseada no "meio-termo", no equilíbrio, tanto no âmbito de si mesmo, como nas relações com o outro. É importante ressaltar, que a noção de ética proposta inicialmente na sociedade grega, busca qualificar a conduta humana ou as "virtudes" como éticas, a partir de uma noção de ética que designa costumes (MORA, 1996). Chalita (2003), baseando-se na "Ética a Nicômacos" de Aristóteles, propõe a observância de preceitos que chama de "Dez mandamentos da ética": fazer o bem; agir com moderação; saber escolher; praticar as virtudes; viver a justiça; valer-se da razão; valer-se do coração; ser amigo; cultivar o amor e ser feliz. Segundo o autor, o exercício de tais preceitos leva para uma vida harmoniosa, para uma vida ética na qual "a vitória conquistada pelo bem é fazer o bem, e a recompensa por agir eticamente é ser ético" (CHALITA, 2003, p. 199).

Um exemplo das diferentes abordagens da ética e sua relação com o contexto social em que se vive é a ética da responsabilidade. Conforme mostra Giacoia Júnior (2000), o acelerado desenvolvimento tecnológico que permite diferentes possibilidades de intervenção humana sobre a natureza, sobre si mesmo e sobre a crise ecológica estão no bojo das discussões que tratam de uma ética que diz respeito ao futuro remoto ou às futuras gerações. $\mathrm{Na}$ ética da responsabilidade, o desafio de um equilíbrio, de uma vida harmoniosa traz presente à compreensão de que há um ambiente no qual nosso agir presente constrói o futuro. Essa preocupação com um futuro é que confere uma novidade nesta abordagem da ética. 
Mas, como ter equilíbrio, uma vida harmoniosa e fazer o bem no exercício de uma profissão, que como visto anteriormente, integra um empreendimento de ordem econômica, política e social? As discussões sobre ética profissional têm em si complexidade porque estão relacionados ao modo como um grupo se organiza, como esse grupo, que tem em comum a aplicabilidade de um conjunto de técnicas, competências e conhecimentos, se relaciona internamente, como as pessoas desse grupo se relacionam com os membros da sociedade, usuários de seus serviços e, também, o que representa esse conhecimento, conjunto de técnicas, competências e sua aplicabilidade para a sociedade.

Em função desta complexidade que envolve interesses políticos, econômicos e sociais, a ética profissional congrega uma carga ideológica que, para Freidson (1998), é percebida exatamente no processo de formação de um grupo que incorpora um empreendimento. Tavares (1986) questiona a eleição de um tipo especial de ética, a ética profissional, evidenciando com isso, diferenças entre membros de grupos profissionais e os demais membros da sociedade. O referido autor explica que a ética é uma preocupação que diz respeito a todas os indivíduos membros da sociedade humana, e ao estabelecer uma ética profissional, pressupõe-se uma distinção entre os "profissionais" e os demais indivíduos. Souza (2002), por sua vez, mostra que por trás da defesa de determinados modos de fazer e inclusive valores éticos universais, há um conjunto de interesses que visam manter a profissão com objetivos de beneficiar os membros do grupo profissional, ampliar uma área de reserva econômica (melhores salários) e mais poder em termos de aplicação do conhecimento da área.

A ética profissional geralmente se institucionaliza nos chamados "códigos de ética". Em se tratando dos "códigos de ética" o termo mais adequado para designar a discussão em torno da conduta profissional seria "deontologia" considerando o significado da mesma. A deontologia representa um conjunto de preceitos, de idéias, um elenco de determinações objetivas, instruções operacionais a serem seguidos pelos membros de uma categoria profissional visando garantir a uniformidade na realização de um trabalho e ação do grupo “como se fosse a ação de um único indivíduo" (SOUZA, 2002, p. 55). Desse modo, para Giddens (1991) os "códigos de ética profissional" representam o controle interno da confiabilidade de colegas e associados. Ou seja, para determinadas situações que representam desafios éticos e/ou morais existem prescrições ou orientações que visam disciplinar ou difundir condutas desejáveis. Isso colabora para a formação de uma identidade do grupo profissional, e indiretamente contribui para a construir e preservar a imagem dos membros de uma dada profissão e ainda, manter sua coesão diante de situações de conflito. 
Pensar numa ética profissional bibliotecária é pensar no ser social do bibliotecário que se constrói no seu agir cotidiano, na sua participação social, política e econômica. Para Souza (2002) os interesses que envolvem a ética profissional, são sinalizados como sete "problemas deontológicos". Conforme esse mesmo autor, a consciência dos mesmos permite uma reflexão preliminar quando na elaboração de códigos deontológicos. Resumidamente, esses problemas são: consciência (sobrepor o seu próprio interesse ao interesse das pessoas da comunidade); liberdade (impor a forma de proceder e o conhecimento da categoria como único reduzindo a liberdade das demais pessoas); autoridade (a existência centrada na legalidade é uma impostura); sobrevivência material (subsistir sem o pagamento de um salário justo não impondo “... à sociedade sua ciência e seu modo de fazer como o único a ser buscado ou comprado"); convivência (reduzir a relação profissional e usuário a um "mero balcão de negócios"); igualdade (valoração diferenciada das especializações que compõem uma profisssão e diferenciação entre as profíssões que disputam espaço); e fraternidade (a relação entre profissional e comprador de seu serviço é desigual) (SOUZA, 2002, p. 76-80).

Esses problemas deontológicos emergem principalmente em função do modelo econômico capitalista "no qual igualdade, liberdade e autoridade são meros rótulos para encobrir abusos" (SOUZA, 2002, p. 80). Romper com a lógica da competição e do individualismo tão difundido nos modos de ser e estar dos membros da sociedade contemporânea representa um desafio que se faz presente quando se trata de "ética profissional", principalmente se a abordagem da temática promover reflexões mais aprofundadas em torno de noções de ética, e os ideais por meio dela difundidos.

Numa análise dos códigos de ética (ou deontológicos) dos bibliotecários Pérez Pulido (2002) realizou um estudo comparativo envolvendo códigos de ética de profissionais bibliotecários e outros profissionais da informação. Em sua análise, a autora, classificou os códigos em aspiracionais; educacionais e disciplinares. Vale notar que o "Código de ética do bibliotecário brasileiro" é categorizado como disciplinar em função do discurso que apresenta, além disso, é calcado na legalidade, o que lhe dá uma carga de autoridade. Esse caráter disciplinar, centrado na legalidade, limita as possibilidades de uma ética nos termos que a situam na busca de um "bem maior" da coletividade, porque impõe um modo de agir que ignora a complexidade das relações humanas e sociais da sociedade contemporânea, bem como a capacidade de participação dos membros da profissão e dos usuários de seus serviços na construção de soluções éticas. 


\section{OS BIBLIOTECÁRIOS COMO TRABALHADORES}

Se uma discussão sobre ética profissional envolve interesses dos membros de uma ocupação organizada, os problemas deontológicos apresentados por Souza (2002) vão ganhar uma amplitude maior em um em mundo do trabalho em processo de mudanças, dado que obter a sobrevivência material é salutar para os indivíduos, de certa forma reforçando a importância de tratar da ética.

Diante do modelo econômico vigente, no último século, a aplicação de conhecimento científico, servindo para inovação e tomada de decisão nos espaços produtivos tem acelerado mudanças nos ambientes de trabalho. Nesse contexto, ocorre uma "imensa flexibilização dos vínculos de trabalho", visível em termos como mudança, risco, reengenharia das corporações, trabalho em rede e em equipes, trabalho por tarefa, trabalho em casa, criatividade, competência, desafios, os quais são correntes em uma realidade na qual há uma crescente precarização das condições de trabalho e a pauperização dos trabalhadores (DOWBOR, 2001). Dowbor (2001, p. 54) destaca que "as pessoas estão trabalhando mais e sentindo mais insegurança, mais estresse e, sobretudo, a perda generalizada do controle de suas vidas".

Para Sennett (2002) o caráter pessoal é colocado em cheque no mundo do trabalho atual. $\mathrm{O}$ autor mostra que o caráter designa os traços pessoais valorizados pelos indivíduos por possuírem um valor ético, o que, na visão do autor, não encontra mais um referencial significativo nas qualidades de um bom trabalho. Sennett (2002) trata do que denomina “corrosão do caráter" quando nas relações de trabalho, noções como lealdade, compromisso mútuo, experiências de longo prazo se perdem diante de um cenário no qual se rompem os compromissos de longo prazo, com um característico desprezo pela burocracia; abertura às mudanças; predisposição para correr riscos e aceitar desafios.

Outra abordagem relevante para essa discussão, é o que Dejours (2000) chama de "banalização da injustiça social". O autor reflete como, neste contexto de competição e individualismo, se aceitam pressões nos ambientes de trabalho tais como: adulterar relatórios e assumir discursos falaciosos no intuito de manter uma pseudo-segurança. O assombroso medo de perder o emprego leva a uma aceitação de condições de trabalho inadequadas, tolerase o desemprego, comete-se atos aos quais se reprova procura-se livrar da responsabilidade para com os outros.

Dowbor (2001), Sennett (2002) e Dejours (2000) contribuem para mostrar a complexidade que envolve discussões que pretendem refletir em torno de uma ética profissional. Da leitura dos autores é possível situar um aspecto que tem envolvido 
profissionais bibliotecários considerando-se experiências profissionais, conversas com bibliotecários e leitura de mensagens em listas de discussão da área biblioteconômica, trata-se da expansão do ensino superior no país.

A expansão do ensino superior no Brasil tem sido notável nos últimos anos, principalmente no aumento do número de universidades criadas. De um lado, está um contexto que configura uma sociedade pós-industrial, na qual as profissões universitárias estão amplamente presentes. De outro lado, um número cada vez maior de pessoas almejando um diploma universitário, buscando uma profissão e, nisso, realização pessoal e sobrevivência econômica. Nessa realidade, a própria concepção de universidade sofre alterações. Chauí (2003) apresenta uma discussão bastante ampla para entender o percurso da universidade e sua relação com a sociedade. A autora destaca que na concepção de universidade como uma organização, a idéia de educação passa para uma nova conotação, em que educar é um serviço que está no rol de todos os demais serviços oferecidos na sociedade atual. Se as noções basilares em torno do conceito de educação se alteram, cabe questionar como a biblioteca, enquanto instituição que tem um papel fundamental no contexto educacional, ao facilitar o acesso à informações, colaborando para os processos de ensino e aprendizagem, se situa nesse contexto. Ou seja, o conceito de biblioteca, como um espaço de difusão e produção de conhecimento, de educação, de instrução, também é afetado nesse processo de mudanças que trata Chauí (2003)? Como a biblioteca é afetada, em que termos e como participa desse processo pode ser um tema de discussão pertinente para a categoria profissional bibliotecária, considerando-se, que as bibliotecas universitárias são um campo de atuação dos bibliotecários. Em relação a ética, cabe indagar se há a emergência de desafios éticos/morais nesse contexto, nas relações que envolvem bibliotecários, empregadores, usuários da instituição de ensino e sociedade como um todo.

\section{A INFORMAÇÃO COMO UM BEM SOCIAL}

O acesso à informação e a capacidade de usá-la são elementos que interferem nas possibilidades de sobrevivência e existência dos membros da sociedade contemporânea. Nessa sociedade, acessar e usar informações interferem no exercício de direitos, na obtenção de emprego e na manutenção do mesmo, o que implica, entre outras coisas, em receber um salário, assim como na capacidade de expressar-se a partir das possibilidades de conhecer e identificar-se. 
O acesso à informação está relacionado à liberdade de se expressar o que aparece como um direito na Declaração Universal dos Direitos Humanos, especialmente em seu artigo 19:

todo o indivíduo tem direito à liberdade de opinião e de expressão, o que implica o direito de não ser inquietado pelas suas opiniões e o de procurar, receber e difundir, sem consideração de fronteiras, informações e idéias por qualquer meio de expressão.

Conforme Pérez Pulido (2002), a concepção da informação como um direito, a partir do que coloca a Declaração Universal dos Direitos Humanos, é a base que fundamenta os códigos de ética de bibliotecários e outros profissionais da informação. A autora mostra essa relação a partir dos artigos 19 Liberdade Intelectual; 3 e 12 Privacidade e confidencialidade; 17 e 27 Propriedade intelectual; 26, 27 e 28 Educação, Cultura e Desenvolvimento da personalidade.

\subsection{Direitos Humanos e uma Ética do Discurso}

Sob uma perspectiva dos direitos humanos, o respeito ao outro implica reconhecer que em cada ser humano há um sujeito de direitos (DIAS, 1994). Na Declaração Universal dos Direitos Humanos propõe-se a defesa da dignidade de cada homem, em qualquer circunstância, lugar ou momento, como um direito incontestável (ARANA MUÑOZ, 1999).

A informação é um dos elementos que se relacionam à realização de uma vida digna, como já descrito anteriormente. E é no exercício de uma ética do discurso que o direito ao acesso à informação e o direito de se expressar, bem como, o respeito dos Direitos Humanos, aparecem como imperativos (DIAS, 1994) para a realização de uma ética do discurso. Isso se dá porque na ética do discurso defende-se a idéia de que a tarefa de argumentar é basicamente comunicativa, o que leva à proposição da participação discursiva para a formação de consenso (HERRERO, 2000). Para formar um consenso, a partir de um discurso argumentativo, a consideração de igualdade entre os participantes remete a questões mais fundamentais como a igualdade e autonomia dos sujeitos em dada sociedade.

Nessa perspectiva, a biblioteca pode ser situada como uma instituição que facilita a obtenção da informação e, a partir disso, seus usuários estariam aptos a participar da sociedade como cidadãos. Se na ética do discurso há a possibilidade de se negociar uma conduta a partir de argumentação racional, tais negociadores devem conhecer de uma forma equilibrada sobre o tema que tratam. A realização dessa abordagem ética já se dá nos chamados comitês de ética presentes em muitas organizações e instituições atuais (LOZANO; SIURANA, 2002). 
Trazendo essas discussões para o âmbito do fazer do profissional bibliotecário, que atua muito diretamente com a informação, as questões citadas a seguir servem para uma reflexão:

a) Quanto ao respeito e reconhecimento dos membros da sociedade como sujeitos de direitos: Como acontece a garantia de acesso à informação àqueles indivíduos que não têm uma autonomia para garantir seus direitos: deficientes (Literatura Braille, serviços para surdos e mudos, rampas adequadas para o acesso a cadeirantes)? Acesso à informação para usuários especiais como idosos, detentos e hospitalizados?

b) Quanto ao exercício de uma ética do discurso na biblioteca. O usuário é convocado para discutir as normas que regem o uso da biblioteca? Esse mesmo usuário é esclarecido adequadamente em relação aos seus direitos e deveres no que diz respeito ao uso da biblioteca? Quais os direitos do usuário da informação, como perguntou Vergueiro (1998) no número 10 do boletim Palavra-Chave?;

c) Em relação à categoria profissional, seu posicionamento é no sentido de orientar seus membros para uma conduta que considere a biblioteca um espaço de direito? No exercício de gerência da biblioteca, em algum momento se negocia a concepção de biblioteca que se aplica? Como garantimos o acesso indiscriminado à informação para o exercício de direitos?.

\section{A BIBLIOTECA COMO UM AMBIENTE DE RELAÇÕES SOCIAIS}

$\mathrm{Na}$ biblioteca vivenciam-se relações sociais. Assim, pessoas trabalham, se formam, se informam, se comunicam, se encontram, portanto interagem numa relação de compartilhamento de conhecimentos e de prestação de serviços. Ao pensar uma ética bibliotecária em bibliotecas é possível estabelecer uma aproximação com a abordagem da ética da alteridade, buscando subsídios para refletir sobre ética a partir de um imperativo ético que reside no encontro com o outro, numa relação responsável com o outro. $\mathrm{Na}$ ética da alteridade, a presença do outro, o encontro com o outro oferece um momento para construção ética, quando seres humanos se reconhecem enquanto tal, a partir do que Levinas (1988) denomina de relação responsável. Relação responsável que permite a identidade enquanto ser humano, um senso de igualdade, de reconhecer-se pelo outro. 


\section{1 Ética da Alteridade}

A (in)capacidade de tolerar o outro em função de diferenças, de sua singularidade, de ver e viver a vida marcam diferentes momentos da história da humanidade. Um exemplo foi o processo de extermínio de povos indígenas na América Latina. Outro exemplo, dentre tantos outros, foi o extermínio de judeus durante a $2^{\mathrm{a}}$ Grande Guerra Mundial. Exemplos estes, que mostram um tipo de extremismo, de intolerância máxima. Porém, a capacidade de agir e reagir diante de fatos e acontecimentos nos permite aprender continuamente e reinventar a vida diante das situações por mais absurdas que se mostrem. Nesse sentido, Emmanuel Levinas (1988), partindo especialmente da perseguição aos semitas, traz para o campo da ética uma nova abordagem: a ética da alteridade.

A ética da alteridade traz presente o rosto do outro. O sujeito em sua relação com o outro tem seu ponto máximo no momento em que se encontra com o outro. Seu discurso, seu conhecimento, suas posturas são colocadas à prova quando vivencia o encontro com o outro porque geralmente seu discurso e seus conhecimentos prévios fazem do outro um objeto. A proposta de uma ética da alteridade implica a idéia de uma relação responsável, na qual o outro não é tomado como objeto, extingue-se a possibilidade de dominação, há o "um-pelooutro" que representa uma quebra do individualismo tão difundido atualmente (PIVATTO, 2000).

Partindo dessas considerações, cabe perguntar, como pensar uma ética em bibliotecas que se construa na relação responsável com o outro? Tal reflexão pode se basear num olhar para si próprio: como eu gostaria de ser atendida na biblioteca? Como me relaciono com o usuário? Que realidade encontra-se no rosto-presença do outro? No cotidiano da biblioteca, dispõe-se de um tempo para a convivência, para encontrar o outro ou o acumulo de tarefas leva a formas de tratamento que consideram tudo e a todos como autômatos, como objetos?

Além de uma aplicabilidade para fins de estudo, essas perguntas servem para refletirmos sobre a percepção da relação com o outro a partir da própria ação, levando à possibilidade de uma construção na qual não há perdedores ou vencedores, há pessoas que estão buscando um agir harmonioso, um agir equilibrado, um agir que respeita, um agir responsável, um agir que por ter todas essas qualidades é um agir no caminho do bem.

\section{CONSIDERAÇÕES FINAIS}


Agir eticamente pode ser um dos desafios dos nossos tempos. Mais do que isso é um exercício diário, um exercício que não ignora a si mesmo, que não ignora o outro, que busca no outro uma relação responsável, que busca no outro a possibilidade de construir um consenso para que as ações de um grupo ou de uma única pessoa promovam o bem maior de um coletivo.

Isso pode ser encarado como um desafio utópico, mas em termos práticos, ousar pensar uma ética bibliotecária acrescenta alguns componentes indispensáveis a esses profissionais e a categoria enquanto grupo organizado: acrescenta-se ao modo de fazer biblioteca, de tratar a informação um componente de responsabilidade; acrescenta uma dimensão de respeito ao outro, de reconhecimento do outro como sujeito de direitos; acrescenta a necessidade de efetivamente conhecer o usuário, não para tê-lo como um objeto, mas para poder se aproximar, negociar e oferecer benefícios ao mesmo; acrescenta também a necessidade de melhorar conhecimentos, competências e técnicas numa proposta que leva ao desenvolvimento intelectual dos membros do grupo e permite a excelência do conhecer e do fazer; acrescenta a necessidade da própria categoria se conhecer melhor e conhecer a sociedade na qual se situa para não ignorar o outro, para não ignorar a dimensão social do ser humano. Sem esses ingredientes não é possível tratar de ética bibliotecária.

\section{REFERÊNCIAS}

ARANA MUÑOZ, J. R. La ética y el hombre. Papeles de Ética, Economía y Dirección, n. 4, 1999. Disponível em: <www.eticaed.org/9.Rodr.Arana99.pdf>. Acesso em: 20 fev. 2004.

ARISTOTELES. Ética : a nicômacos. 2. ed. Brasília: Ed. UnB, 1985.

BERGER, P. L.; LUCKMANN, T. A construção social da realidade. 12. ed. Petrópolis: Vozes, 1995.

CHALITA, G. Os dez mandamentos da ética. Rio de Janeiro: Nova Fronteira, 2003.

CHAUÍ, Marilena. A universidade pública sob nova perspectiva. 2003. Disponível em: $<$ http://www.portoalegre.rs.gov.br//fme/up_arquivo//Conferência\%20Marilena\%20Chauí.doc >. Acesso e:m 15 out. 2003.

DECLARAÇÃO Universal dos Direitos Humanos. Disponível em: $<$ http://www.direitoshumanos.usp.br/documentos/tratados/internacionais/declaracao_universa 1_dos_direitos_humanos.html>.Acesso em: 15 out. 2003

DEJOURS, C. A banalização da injustiça social. 3. ed. Rio de Janeiro: FGV, 2000. DIAS, M. C. De la ética del discurso a la moral del respecto universal. Bogotá, 1994. 
Disponível em: $<$ http://www.ifcs.ufrj.br/cefm/publicacoes/derechoshumanos.pdf $>$. Acesso em: 18 fev. 2004.

DOWBOR, L. O que acontece com o trabalho. São Paulo: SENAC, 2001.

FREIDSON, E. O renascimento do profissionalismo: teoria, profecia e política. São Paulo: Ed USP, 1998.

GIACOIA JÚNIOR, O. Hans Jonas: o princípio responsabilidade. In: OLIVEIRA, M. A. de (Org.) Correntes fundamentais da ética contemporânea. Petrópolis: Vozes, 2000. p. 193206.

GIDDENS, A. As conseqüências da modernidade. São Paulo: Ed UNESP, 1991.

HERRERO, F. J. Ética do discurso. In: OLIVEIRA, Manfredo A. de (Org.) Correntes fundamentais da ética contemporânea. Petrópolis: Vozes, 2000. p. 163-192.

LEVINAS, E. Ética e infinito: diálogos com Philippe Nemo. Lisboa: Edições 70, 1998.

LOZANO, J. F.; SIURANA, J. C. Las comisiones éticas como mecanismo de integración de la ética en las organizaciones. Papeles de Ética, Economía y Dirección, n. 5, 2002.

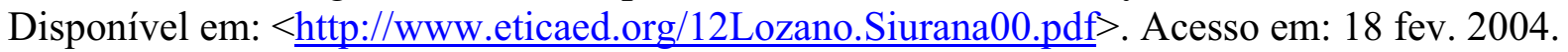

MORA, J. F. Ética. In. Dicionário de Filosofia. São Paulo: Martins Fontes, 1996. p. 245-252.

MORIN, E., et al. A sociedade em busca de valores: para fugir à alternativa entre o cepticismo e o dogmatismo. Lisboa: Instituto Piaget, 1996.

PÉREZ PULIDO, M. Códigos de ética de los bibliotecarios y otros profesionales de la información: comentario y análisis comparativo. ANABAD, Espanha, jul/ago. 2002. p. 1-19. Disponível em: <: http://www.anabad.es/documentos/>. Acesso em: 18 fev. 2004.

PIVATTO, P. S. Ética da alteridade. In: OLIVEIRA, Manfredo A. de (Org.) Correntes fundamentais da ética contemporânea. Petrópolis: Vozes, 2000. p. 79-98.

SENNETT, R. A corrosão do caráter: conseqüências pessoais do trabalho no novo capitalismo. 6. ed. Rio de Janeiro: Record, 2002.

SOUZA, F. das C. de. Ética e deontologia: textos para profissionais atuantes em bibliotecas. Florianópolis: Ed UFSC, 2002.

TAVARES, J. C. Fundamentos teóricos para uma deontologia profissional. 1986. Disponível em : $<\underline{\text { http://www.elo.com.br/^}{ }^{\wedge} \text { cynthia/deonto.htm> }}$. Acesso em: 27 jan. 2004.

VERGUEIRO, W. C. S. As bibliotecas, os centros de informação e o consumidor (ou vá se queixar ao bispo, antes que eu me esqueça!). Palavra Chave, São Paulo, n. 10, p. 3-7, abr. 1998. 


\begin{abstract}
It approaches the librarian ethics comprehending the Librarianship constitution from a systemic view. In this way, with the objective to raise issues to discuss professional ethics, it places the librarian in the work world and points approaches between exertion and relation context of the professionals themselves with the human rights and alteration ethics.
\end{abstract}

KEY-WORDS: Librarianship Ethics. Ethics and Information. Ethics in Libraries.

Originais recebidos em 04/10/2004 